\title{
PROCESS AND SYSTEMS Patient-completed safety checklists as an empowerment tool for patient involvement in patient safety: concepts, considerations and recommendations
}

\author{
Authors: Kristin Harris ${ }^{\mathrm{A}_{*}}$ and Stephanie Russ ${ }^{\mathrm{B} *}$
}

The application of safety checklists to healthcare settings to help systematise routines and improve communication between healthcare professionals has proven to be effective in reducing errors, complications, mortality and hospitalisation time. There is a new call to extend the checklist concept to develop safety checklists that can be used by patients to help empower their involvement in safety practices. Only a handful of studies around patient-completed checklists exist, but those that do indicate a positive impact on patient empowerment and involvement in safety-related behaviours. In this article, we present the concept of patientcompleted checklists and provide a review of the existing evidence, highlighting important design and implementation considerations, and making recommendations for future research and development.

KEYWORDS: patient safety, patient involvement, patient empowerment, patient-completed checklists

DOI: $10.7861 /$ fhj.2021-0122

\section{Empowering patient involvement in safety}

Patient involvement in healthcare design and delivery is recognised as a key factor for driving improvements in the quality of care and is a central tenet of national and international patient safety strategies. ${ }^{1,2}$ In developed healthcare systems, this is evidenced by an ongoing cultural shift from medical paternalism towards a patient partnership model, where patients are seen as equal stakeholders and contributors to their care decisions and conversations. ${ }^{3,4}$ Evidence suggests that patients who are able to be involved are willing to be involved across many levels of healthcare, and that 'patient empowerment' is an important enabler for this. ${ }^{5-8}$ A number of studies have reported

Authors: ${ }^{A} \mathrm{PhD}$ candidate, Haukeland University Hospital, Bergen, Norway, Western Norway University of Applied Sciences, Bergen, Norway and University of Bergen, Bergen, Norway; ${ }^{B}$ senior research fellow, King's College London, London, UK; * joint first authors a relationship between increased patient empowerment and better healthcare outcomes, such as wellbeing, self-management, mental and physical health status, health-related quality of life, and cost-effectiveness. ${ }^{9-16}$ Therefore, a focus on understanding how best to empower patients is key.

Patient involvement in patient safety specifically has gained more prominence as a result of growing awareness and reporting of serious clinical and service failings, often championed by friends and relatives of those who have come to harm. However, despite examples of patient and public involvement in the quest to improve safety, there is still uncertainty about how to do it well and in ways that constitute genuine partnerships. ${ }^{3,4,17,18}$ Patients are uniquely placed to contribute towards safety in healthcare settings, including the mitigation of errors and adverse events. With exceptions, patients often have expertise in their own conditions and can fill gaps in their medical history, and they observe the whole process of care as it happens around them, unlike healthcare staff who come and go. This may allow them to spot inconsistencies and omissions in their care where others may not be able to, adding resource to the system for trapping errors. ${ }^{19}$ However, one thing that has become clear is that the role of healthcare professionals in encouraging patients to be involved in safety is hugely important, without which, patients may feel they are imposing or stepping beyond accepted patient-clinician boundaries. Clinicians can, therefore, help to empower patient involvement in a number of respects; for example, by welcoming questions and challenges, and by encouraging shared decision making and participation in discussions and safety checks. ${ }^{6,18,20}$

Equally as important as the role of clinicians in fostering patient involvement is the very practical need to show patients how they can help to optimise the safety of their care and to provide them with the tools and information they require for doing so.

\section{Safety checklists as a tool for patient empowerment}

The use of safety checklists is no longer a novel concept in healthcare. Originating from aviation and other high-risk industries, we have in the past 15 years increasingly seen checklists adapted for a range of healthcare settings for use by clinical teams, with the aim of improving the reliability of care and reducing adverse events. When supported by a thoughtful implementation approach with attention to the local context and culture, such checklists can result in significant benefits to patient 
outcomes. Some of the most high-profile examples include the World Health Organization Surgical Safety Checklist, the Surgical Patient Safety System (SURPASS) and the Michigan Keystone checklist. $^{21-25}$

Checklists work via a combination of active mechanisms. At a basic level they help to standardise processes and procedures and provide cognitive prompts or reminders for the completion of evidence-based practises, which helps in the detection and prevention of error-inducing conditions. At a more complex level, they encourage behaviour change to create an atmosphere of effective communication and a shift in the perception of social norms resulting in an improved culture for safety. One of the key mechanisms of action of checklists is to engender a shared mental model across the team by empowering all members of the team to have a voice and to support communication at critical times. ${ }^{26}$

This prompts the question of whether checklists might be adapted for use by patients to empower their involvement in improving safety in a similar way. They might serve as a tool for helping patients to seek information they require to make decisions about their care; they might inform patients of the kind of information they should provide to optimise their care; they might prompt patients to ask questions to aid understanding; they might educate patients on the warning signs that they can look out for or safety-related behaviours they can engage in; and, perhaps most importantly, they might give patients the permission they need to speak up as part of the care team.

\section{Current examples of patient-completed checklists}

While the current evidence base for 'patient-completed' safety checklists is modest, there are examples emerging in the literature that demonstrate how such checklists might look, how they might be integrated into care processes and pathways, and how they might positively impact care (see Table 1 for summary of findings).

Four studies have reported on patient-completed safety checklists for use in the context of surgical care. Hardiman and colleagues designed and implemented a postoperative self-care checklist for patients who had undergone ileostomy surgery to help them care for their ileostomy post-discharge. ${ }^{27}$ Shirley et al developed a checklist for parents to use prior to providing informed consent for their child's surgery with the aim of increasing understanding of important information, including potential risks and alternative treatment options. ${ }^{28}$ Russ et al developed a patient-completed surgical safety checklist delivered via an animated smartphone app for patients undergoing surgery in the UK's NHS. The 'MySurgery' app is centred around key areas of evidence-based risk involved in having any surgical procedure and is designed to be used by patients and their carers prior to, during and following their surgical admission. It provides information and practical step-by-step advice on the actions they can take to help mitigate risk, promoting behaviours that will reduce susceptibility to error or complications, and encouraging discussion with healthcare professionals. ${ }^{29,30}$ Finally, Harris et al report on a checklist for surgical patients in Norway. The checklist is centred around several areas of risk identified throughout the surgical pathway that patients can potentially influence to reduce risk of errors and complications. The checklist is designed in two sections. One addressing safety issues, important information and preparations pre-surgery; the second guiding patients through the discharge process by encouraging them to ask for important information regarding complications, medications, further treatment and follow-up post-surgery. ${ }^{31,32}$

Two patient-completed checklists were identified outside of surgical care. The first has been developed to assist elderly inpatients to participate in their discharge planning and make practical arrangements for living at home. ${ }^{33,34}$ The second evaluates a checklist delivered via smartphone app for patients undergoing systemic cancer treatment to help them identify potential common complications related to their cancer treatment at home and to allow nurses to monitor symptom development via a shared dashboard. ${ }^{35}$

While these studies are small in size and require further followup to assess the impact on process and clinical outcomes, they support the notion that patient-completed safety checklists might offer an effective tool for empowering patients to become involved in their care, as well as offering additional benefits to patient experience and outcomes.

\section{Reflections and important considerations}

The issue of 'responsibility'

When it comes to patient involvement in safety, the question of 'responsibility' has been the topic of much debate and is likely to be raised in the case of patient-completed safety checklists. Should patients be expected to play a role in keeping themselves safe in healthcare settings? Should this be left to the professionals? Recent research suggests that patients' perspectives about 'responsibility' for safety in healthcare settings are complex, but that most are supportive of the notion of shared responsibility for safety between staff and patients. Expertise in one's own health, a duty of self-care and a duty to behave appropriately have all been cited by patients as reasons why they should take on a degree of responsibility to help keep themselves safe in healthcare settings. ${ }^{36}$ This view is in keeping with the 'systems approach' to patient safety, where safety is seen to be a function of multiple interplaying factors at different levels of the organisation, including the role of the patient, as opposed to individual clinician responsibility. Patient-completed safety checklists can play a role here in showing patients how they can take on some responsibility for their safety when they enter care settings, giving them the information and levers they need to help mitigate risk. It will, however, be important to reassure patients that their use of checklists is just one part of a suite of recommended safety practices, not something that carries any formal/legal accountability should anything go wrong with their care.

\section{Checklist design}

The process involved in designing patient-completed safety checklists is not consistently reported. We know from other areas of healthcare that checklist design is likely to significantly influence buy-in, use and impact, and therefore understanding how previous lessons apply to the design of patient checklists, as well as understanding important design features that are exclusive to patient checklists, is an important consideration. We have collated the available guidance around patient-completed safety checklist design in Box 1. ${ }^{29,37,38}$ One principle that is becoming better understood is the importance of involving diverse groups of patients and service users when designing patient empowerment 
Table 1. Summary of published patient-completed checklists

\begin{tabular}{|c|c|c|c|c|c|c|}
\hline \multirow[t]{2}{*}{ Authors } & \multirow{2}{*}{$\begin{array}{l}\text { Specialty I } \\
\text { care area }\end{array}$} & \multirow{2}{*}{$\begin{array}{l}\text { Type of } \\
\text { checklist }\end{array}$} & \multirow[t]{2}{*}{ Aim of checklist } & \multicolumn{2}{|c|}{ Principle findings } & \multirow[b]{2}{*}{$\begin{array}{l}\text { Clinical } \\
\text { outcomes }\end{array}$} \\
\hline & & & & Acceptability & Impact on care & \\
\hline $\begin{array}{l}\text { Hardiman } \\
\text { et al, } 2016^{27}\end{array}$ & $\begin{array}{l}\text { Colorectal } \\
\text { surgery }\end{array}$ & $\begin{array}{l}\text { Paper-based } \\
\text { postoperative } \\
\text { self-care } \\
\text { checklist for } \\
\text { ileostomy } \\
\text { patients }\end{array}$ & $\begin{array}{l}\text { Help patients } \\
\text { understand how } \\
\text { to care for their } \\
\text { ileostomy prior to } \\
\text { discharge and to } \\
\text { reduce readmission }\end{array}$ & $\begin{array}{l}\text { Patients willing } \\
\text { to use the } \\
\text { checklist }\end{array}$ & $\begin{array}{l}\text { Enabled patients } \\
\text { to better report } \\
\text { measures of } \\
\text { output and skin } \\
\text { issues enabling } \\
\text { early intervention } \\
\text { by phone }\end{array}$ & $\begin{array}{l}\text { Reduction in } \\
\text { readmission rate } \\
\text { from } 28 \% \text { to } \\
20 \%\end{array}$ \\
\hline $\begin{array}{l}\text { Shirley et al, } \\
2021^{28}\end{array}$ & $\begin{array}{l}\text { Paediatric } \\
\text { orthopaedic } \\
\text { surgery }\end{array}$ & $\begin{array}{l}\text { Eight-item } \\
\text { paper-based } \\
\text { preoperative visit } \\
\text { checklist }\end{array}$ & $\begin{array}{l}\text { Increase patient } \\
\text { understanding } \\
\text { of discrete } \\
\text { components of the } \\
\text { surgical consent } \\
\text { process }\end{array}$ & Not reported & $\begin{array}{l}\text { Scored } \\
\text { positively for } \\
\text { enabling better } \\
\text { understanding of } \\
\text { the surgery and } \\
\text { helping patients } \\
\text { to ask questions }\end{array}$ & Not reported \\
\hline $\begin{array}{l}\text { Russ et al, } \\
2020^{29,30}\end{array}$ & $\begin{array}{l}\text { Any surgical } \\
\text { procedure }\end{array}$ & $\begin{array}{l}\text { Smartphone } \\
\text { app, } \\
\text { 'MySurgery', } \\
\text { that acts as a } \\
\text { patient-checklist } \\
\text { and information } \\
\text { guide }\end{array}$ & $\begin{array}{l}\text { Inform patients } \\
\text { about evidence- } \\
\text { based risks } \\
\text { involved in surgical } \\
\text { procedures/actions } \\
\text { to reduce error and } \\
\text { complications }\end{array}$ & $\begin{array}{l}\text { Patients agreed } \\
\text { that the app } \\
\text { was acceptable, } \\
\text { appropriate and } \\
\text { easy to use }\end{array}$ & $\begin{array}{l}\text { Empowered } \\
\text { patients to ask } \\
\text { questions / } \\
\text { become involved } \\
\text { in conversations } \\
\text { with their } \\
\text { healthcare } \\
\text { team; increased } \\
\text { awareness } \\
\text { of risk-/ } \\
\text { safety-related } \\
\text { behaviours }\end{array}$ & Not reported \\
\hline $\begin{array}{l}\text { Harris et al, } \\
2020^{31,32}\end{array}$ & $\begin{array}{l}\text { Any surgical } \\
\text { procedure }\end{array}$ & $\begin{array}{l}\text { Electronic } \\
\text { perioperative } \\
\text { checklist }\end{array}$ & $\begin{array}{l}\text { Empower patients } \\
\text { to be involved in } \\
\text { their own health } \\
\text { and safety to reduce } \\
\text { the patients' risk of } \\
\text { complications and } \\
\text { errors }\end{array}$ & $\begin{array}{l}\text { Patient and } \\
\text { healthcare } \\
\text { workers express } \\
\text { a need for a } \\
\text { surgical checklist }\end{array}$ & $\begin{array}{l}\text { Planned to be } \\
\text { investigated } \\
\text { in upcoming } \\
\text { clinical trial }\end{array}$ & $\begin{array}{l}\text { Clinical trial } \\
\text { (started } \\
\text { October 2021), } \\
\text { NCT03105713 }\end{array}$ \\
\hline $\begin{array}{l}\text { Grimmer } \\
\text { et al, } 2006^{33,34}\end{array}$ & $\begin{array}{l}\text { Discharge } \\
\text { planning } \\
\text { following } \\
\text { medical } \\
\text { admissions }\end{array}$ & $\begin{array}{l}\text { Paper-based } \\
\text { discharge } \\
\text { planning } \\
\text { checklist given } \\
\text { to patients at } \\
\text { admission to } \\
\text { hospital }\end{array}$ & $\begin{array}{l}\text { Help patients } \\
\text { consider and plan } \\
\text { for practical issues } \\
\text { related to hospital } \\
\text { discharge home to } \\
\text { prevent concerns } \\
\text { and problems after } \\
\text { discharge }\end{array}$ & $\begin{array}{l}\text { Eighty-nine per } \\
\text { cent of patients } \\
\text { reported the } \\
\text { checklist relevant; } \\
81 \% \text { of patients } \\
\text { thought the } \\
\text { checklist contents } \\
\text { assisted with } \\
\text { practical issues }\end{array}$ & $\begin{array}{l}\text { Significantly } \\
\text { improved } \\
\text { preparedness } \\
\text { for discharge, } \\
\text { particularly when } \\
\text { a family member } \\
\text { was involved }\end{array}$ & Not reported \\
\hline $\begin{array}{l}\text { Jones et al, } \\
2020^{35}\end{array}$ & Oncology & $\begin{array}{l}\text { Smartphone app } \\
\text { with a linked } \\
\text { dashboard } \\
\text { viewable by } \\
\text { clinicians; to be } \\
\text { used daily by } \\
\text { patients during } \\
\text { treatment }\end{array}$ & $\begin{array}{l}\text { Help patients, } \\
\text { their 'safety } \\
\text { buddies' and the } \\
\text { clinical team to } \\
\text { monitor symptom } \\
\text { development and } \\
\text { to flag common } \\
\text { complications of } \\
\text { systemic cancer } \\
\text { treatment }\end{array}$ & $\begin{array}{l}\text { Patients agreed } \\
\text { that the app was } \\
\text { helpful }\end{array}$ & $\begin{array}{l}\text { Patients reported } \\
\text { that they felt } \\
\text { safer with the } \\
\text { checklist }\end{array}$ & $\begin{array}{l}\text { Patients using the } \\
\text { checklist required } \\
32 \text { vs } 97 \text { nights of } \\
\text { the hospital days } \\
\text { with overnight } \\
\text { stay compared } \\
\text { with patients who } \\
\text { did not use the } \\
\text { checklist (non- } \\
\text { significant) }\end{array}$ \\
\hline
\end{tabular}


Box 1. Important design considerations for patientcompleted checklists

> Identify the 'risks' that the checklist should address in cooperation with stakeholders (ie patients, clinicians and hospital management).

> Ensure the objectives of the checklists are communicated clearly in the checklist itself and use a title that reflects the objectives.

Draft checklist items, with consideration of the following:

$>$ no more than 10 items per heading / pause point

$>$ the language is simple and jargon-free

$>$ a clear font (eg sans serif), with dark text on a light background

$>$ ensure each item has a clear recommendation on the required action.

$>$ Include instructions on how to use the checklist.

> Where possible, ensure that the checklist adjusts itself depending on the relevance of item to avoid patients having to answer too many irrelevant questions.

> Plan when the checklist should be used, considering how it will be integrated with existing processes and procedures, utilising natural breaks or opportunities in the workflow.

> Consider how the checklist can be adapted to suit different units/teams/contexts.

\section{Where the checklist is electronic}

$>$ Include instructions on how to download and update the checklist.

Test the usability of the digital interface.

Ensure adequate data protection systems are in place.

$>$ Consider how the checklist will be accessible to those who cannot use a digital device.

tools, so that their views, knowledge and experience are represented and can be built into it and any potential barriers to use can be anticipated. ${ }^{2,29}$

\section{Checklist accessibility}

Some of the research emerging around patient-completed safety checklists has highlighted the issue of accessibility, particularly when delivered via digital devices. If a safety intervention is accessible to some but not others, there is a moral issue in terms of equity of healthcare. Research to date has identified a number of patient groups who may experience issues with accessing patient-completed checklists. These include those with visual impairments; learning difficulties; dementia; mental health illnesses; multimorbidity; language barriers; and, where checklists are delivered electronically, those who struggle with digital literacy, don't own a digital device or can't access the necessary data/ wifi required. Other groups of patients may be able to access a checklist but may be inhibited to use the information contained within it; for example, in certain cultures, it is not deemed appropriate to challenge figures of authority or to step beyond the traditional role of the passive/subordinate patient. Likewise, individuals with more passive personality types may find it difficult to use checklists, particularly where they involve challenging clinicians or becoming more involved in care conversations. $5,28,29,35$ This underlines the importance of involving diverse groups of patients in the concept testing and design phases of checklist development, which will enable a broader understanding of potential barriers to accessing these tools and an exploration of alternative engagement strategies.

\section{Implementation approach}

The introduction of safety checklists into healthcare settings has not been without challenges. Despite widespread evidence for their positive impact on patient care, we have seen problems with application, with fidelity of use and in generating enthusiasm for their adoption among clinical teams. Many of these problems have been linked to the implementation approach undertaken when first introducing the checklists and in fostering their ongoing use. ${ }^{39,40}$ We have learnt that a carefully planned and multi-faceted implementation approach that considers the local context, involves key stakeholders and is iteratively adjusted to take into account organisational and team dynamics is key. Other components of an effective checklist implementation approach have included educating clinical teams around checklists usage, providing feedback to teams on the impact of checklist use locally, clear leadership in checklist use from hospital management and senior clinical staff, customising checklists, and integrating them with existing systems, processes and procedures..$^{40-43}$ These powerful lessons should be applied to the implementation of patient-completed safety checklists and we should seek to understand where different barriers and facilitators to implementation may arise. One challenge that features repeatedly in the analysis of barriers to the effective implementation of safety interventions is the lack of an adequate organisational safety culture for embracing a change. ${ }^{41-47}$ It is not unreasonable to assume that the introduction of patient-completed checklists, alongside the idea of patients playing a more active role in their care, might be met with similar cultural challenges. Close attention to cultural factors (eg staff acceptance of the tools and the impact on patient-clinician interactions) should, therefore, be built into the development and evaluation of patient-completed safety checklists and it will be critical to closely involve healthcare workers and management at each stage to support broad stakeholder buy-in.

\section{Next steps}

Given the heterogeneity of research designs in the area to date, a focus going forward should be to conduct robust studies with appropriate outcome measures for allowing a comprehensive understanding of the impact of patient-completed safety checklists. So far, evaluation has focused on their acceptability, use and impact on patient experience, with sparse consideration of process measures or clinical outcomes. We should, therefore, seek to include outcomes that relate to the core objectives of patient-completed safety checklists that are to improve patient empowerment and to enhance safety. Thus, validated measures of patient empowerment, as well as impact on clinical teams' work processes and clinical outcomes associated with safety (including hospitalisation time and incidence of preventable complications and errors), will be important indicators of their efficacy. The impact on safety culture should also be explored. Additionally, it will be important to distil and share lessons around how to best develop, design and validate patient-completed checklists. Alongside the design considerations presented in Box 1 , we have provided guidance on steps to consider when developing 


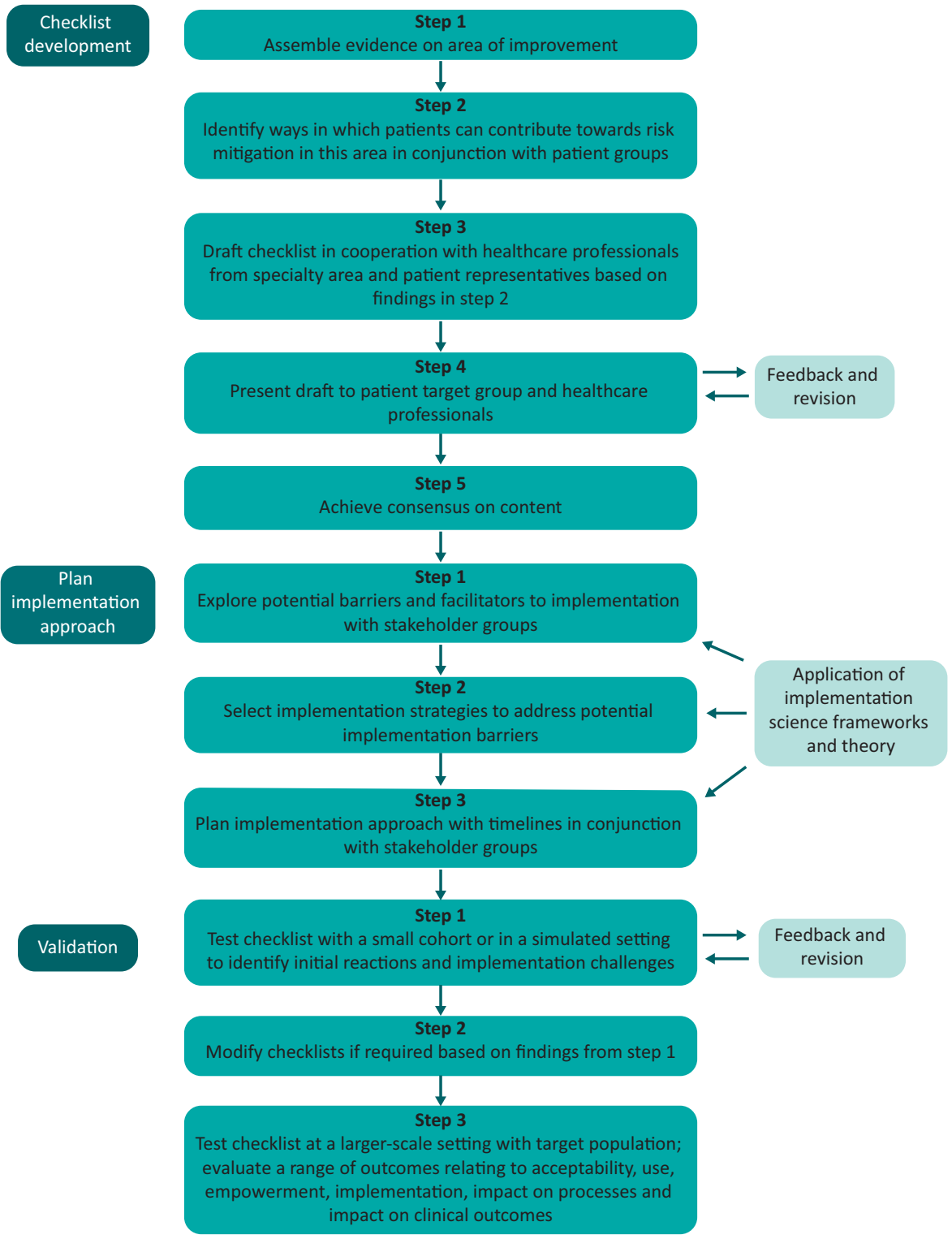

Fig 1. How to best develop, design and validate patient-completed checklists.

and validating these tools based on available literature and our experiences in developing patient-completed checklists (Fig 1). It is important that we review and update this guidance as we develop understanding of how to optimise the impact of these tools on the quality and safety of care.

Finally, in light of the implementation challenges we have met regarding clinician-focused safety checklists, we should predict that a focus on implementation will be key to realising the potential benefits of patient-completed safety checklists. The field of implementation science offers a range of tools that can help to facilitate in this endeavour, and we should apply this scientific approach moving forward. The aim in undertaking a sciencedriven approach to implementation is that the benefits of patientcompleted safety checklists can be maximised, and it becomes possible to generalise lessons across studies, due to the robust approach undertaken. ${ }^{48,49}$

\section{Conclusion}

Here, we introduced the concept of patient-completed safety checklists as a tool for empowering patients to become involved in patient safety. While the current evidence base does not allow for a robust understanding of the benefits and effects of such checklists, particularly regarding their impact on clinical outcomes, their use has demonstrated a number of positive impacts on patient empowerment and experience. This represents an important step forward in healthcare safety research in terms of offering a practicable approach to involving patients in safety and increasing the resource available for mitigating errors, adverse events and complications before they occur. Understanding how best to implement patient-completed safety checklists will be key to realising their benefit and should be a priority area for research focus moving forward. 


\section{Acknowledgements}

We would like to give our gratitude to Chris Subbe for inviting us to write this review on patient-completed checklist to empower patients to be involved in safety, without his invitation, this review would not have been produced.

\section{References}

1 NHS England, NHS Improvement. The NHS Patient Safety Strategy: Safer culture, safer systems, safer patients. NHS, 2019. https://apo.org. au/sites/default/files/resource-files/2019-07/apo-nid247101_5.pdf

2 World Health Organization. Global Patient Safety Action Plan 2021-2030 towards eliminating avoidable harm in health care. WHO, 2021. www.who.int/publications/i/item/9789240032705

3 Ocloo J, Garfield S, Franklin BD et al. Exploring the theory, barriers and enablers for patient and public involvement across health, social care and patient safety: a systematic review of reviews. Health Res Policy Syst 2021;19:8.

4 Ocloo J, Matthews R. From tokenism to empowerment: progressing patient and public involvement in healthcare improvement. BMJ Qual Saf 2016;25:626-32.

5 Ringdal M, Chaboyer W, Ulin K et al. Patient preferences for participation in patient care and safety activities in hospitals. BMC Nurs 2017;16:69.

6 Davis RE, Sevdalis N, Pinto A et al. Patients' attitudes towards patient involvement in safety interventions: results of two exploratory studies. Health Expect 2013;16:e164-76.

7 Doherty C, Stavropoulou C. Patients' willingness and ability to participate actively in the reduction of clinical errors: A systematic literature review. Soc Sci Med 2012;75:257-63.

8 Organization World Health. Health 2020: a European policy framework and strategy for the 21st century. WHO, 2013.

9 Barr PJ, Scholl I, Bravo P et al. Assessment of patient empowerment a systematic review of measures. PLoS One 2015;10:e0126553.

10 Agner ], Braun KL. Patient empowerment: A critique of individualism and systematic review of patient perspectives. Patient Educ Couns 2018;101:2054-64.

11 Pekonen A, Eloranta S, Stolt M et al. Measuring patient empowerment - A systematic review. Patient Educ Couns 2020;103:777-87.

12 Braun V, Clarke V. Using thematic analysis in psychology. Qual Res Psychol 2006;3:77-101.

13 Londoño AM, Schulz PJ. Influences of health literacy, judgment skills, and empowerment on asthma self-management practices. Patient Educ Couns 2015;98:908-17.

14 Suter P, Suter WN, Johnston D. Theory-based telehealth and patient empowerment. Popul Health Manag 2011;14:87-92.

15 Jerofke T, Weiss M, Yakusheva O. Patient perceptions of patientempowering nurse behaviours, patient activation and functional health status in postsurgical patients with life-threatening longterm illnesses. J Adv Nurs 2014;70:1310-22.

16 Hibbard JH, Greene J, Overton V. Patients with lower activation associated with higher costs; delivery systems should know their patients' 'scores'. Health Aff (Millwood) 2013;32:216-22.

17 Bravo P, Edwards A, Barr P] et al. Conceptualising patient empowerment: a mixed methods study. BMC Health Serv Res 2015;15:252.

18 Hahn DL, Hoffmann AE, Felzien M et al. Tokenism in patient engagement. Fam Pract 2017;34:290-5.

19 Vincent C. Patient safety. Wiley, 2011:290-306.

20 Trier $\mathrm{H}$, Valderas JM, Wensing $\mathrm{M}$ et al. Involving patients in patient safety programmes: A scoping review and consensus procedure by the LINNEAUS collaboration on patient safety in primary care. Eur J Gen Pract 2015;21 Suppl(sup 1):56-61.

21 Haynes AB, Weiser TG, Berry WR et al. A surgical safety checklist to reduce morbidity and mortality in a global population. $N$ Engl J Med 2009;360:491-9.
22 Storesund A, Haugen AS, Flaatten $\mathrm{H}$ et al. Clinical efficacy of combined surgical patient safety system and the World Health Organization's checklists in surgery: a nonrandomized clinical trial. JAMA Surg 2020;155:562-70.

23 Haugen AS, Søfteland E, Almeland SK et al. Effect of the World Health Organization checklist on patient outcomes: a stepped wedge cluster randomized controlled trial. Ann Surg 2015;261:821-8.

24 Pronovost P, Needham D, Berenholtz S et al. An intervention to decrease catheter-related bloodstream infections in the ICU. N Engl J Med 2006;355:2725-32.

25 de Vries EN, Hollmann MW, Smorenburg SM et al. Development and validation of the SURgical PAtient Safety System (SURPASS) checklist. Qual Saf Health Care 2009;18:121-6.

26 Weiser TG, Berry WR. Review article: perioperative checklist methodologies. Can J Anaesth 2013;60:136-42.

27 Hardiman KM, Reames CD, McLeod MC et al. Patient autonomycentered self-care checklist reduces hospital readmissions after ileostomy creation. Surgery 2016;160:1302-8.

28 Shirley E, Mai VH, Neal KM et al. Can a checklist improve the informed consent process? Cureus 2021;13:e13148.

29 Russ S, Sevdalis N, Ocloo J. A smartphone app designed to empower patients to contribute toward safer surgical care: qualitative evaluation of diverse public and patient perceptions using focus groups. JMIR Mhealth Uhealth 2021;9:e24065.

30 Russ S, Latif Z, Hazell AL et al. A smartphone app designed to empower patients to contribute toward safer surgical care: community-based evaluation using a participatory approach. JMIR Mhealth Uhealth 2020;8:e12859.

31 Harris K, Søfteland E, Moi AL et al. Patients' and healthcare workers' recommendations for a surgical patient safety checklist - a qualitative study. BMC Health Serv Res 2020;20:43.

32 Haukeland University Hospital. Development and implementation of patient safety checklists before, during and after in-hospital surgery (PASC): ClinicalTrials.gov Identifier: NCT03105713. ClinicalTrials.gov, 2021.

33 Grimmer K, Moss ], Falco ] et al. Incorporating patient and carer concerns in discharge plans: the development of a practical patient-centred checklist. IJAHSP 2006;4.

34 Grimmer K, Dryden LR, Puntumetakul R et al. Incorporating patient concerns into discharge plans: evaluation of a patient generated checklist. IJAHSP 2006;4.

35 Jones HV, Smith H, Cooksley T et al. Checklists for complications during systemic cancer treatment shared by patients, friends, and health care professionals: prospective interventional cohort study. JMIR Mhealth Uhealth 2020;8:e19225.

36 Heavey E, Waring J, De Brún A et al. Patients' conceptualizations of responsibility for healthcare: a typology for understanding differing attributions in the context of patient safety. J Health Soc Behav 2019;60:188-203.

37 Fernando RJ, Shapiro FE, Rosenberg NM et al. Concepts for the development of a customizable checklist for use by patients. J Patient Saf 2019;15:18-23.

38 Projectcheck.org. Checklist for checklists. Projectcheck.org. www. projectcheck.org/checklist-for-checklists.html

39 Leape LL. The checklist conundrum. N Engl J Med 2014;370:1063-4.

40 Weiser TG, Haynes AB. Ten years of the Surgical Safety Checklist. Br J Surg 2018;105:927-9.

41 Conley DM, Singer SJ, Edmondson L et al. Effective surgical safety checklist implementation. J Am Coll Surg 2011;212:873-9.

42 Russ SJ, Sevdalis N, Moorthy K et al. A qualitative evaluation of the barriers and facilitators toward implementation of the WHO surgical safety checklist across hospitals in England: lessons from the "Surgical Checklist Implementation Project". Ann Surg 2015;261:81-91.

43 Bergs J, Lambrechts F, Simons P et al. Barriers and facilitators related to the implementation of surgical safety checklists: a 
systematic review of the qualitative evidence. BMJ Qual Saf 2015;24:776-86.

44 Haynes AB, Weiser TG, Berry WR et al. Changes in safety attitude and relationship to decreased postoperative morbidity and mortality following implementation of a checklist-based surgical safety intervention. BMJ Qual Saf 2011;20:102-7.

45 Kawano T, Taniwaki M, Ogata K et al. Improvement of teamwork and safety climate following implementation of the WHO surgical safety checklist at a university hospital in Japan. J Anesth 2014:28:467-70

46 Hill MR, Roberts MJ, Alderson ML et al. Safety culture and the 5 steps to safer surgery: an intervention study. $\mathrm{Br}$ ] Anaesth 2015;114:958-62.

47 Haugen AS, Søfteland E, Sevdalis N et al. Impact of the Norwegian National Patient Safety Program on implementation of the WHO
Surgical Safety Checklist and on perioperative safety culture. BMJ Open Qual 2020;9:e000966.

48 Tabak RG, Khoong EC, Chambers DA et al. Bridging research and practice: models for dissemination and implementation research. Am J Prev Med 2012;43:337-50.

49 Nilsen P. Making sense of implementation theories, models and frameworks. Implement Sci 2015;10:53.

Address for correspondence: Kristin Harris, Department of Health and Caring Sciences, Western Norway University of Applied Sciences, Inndalsveien 28, 5063 Kronstad, Bergen, Norway. Email: kristin.harris@hvl.no 